\title{
Frames of spatial reference in Kilivila
}

\author{
Gunter Senft \\ Max-Planck-Institute for Psycholinguistics
}

Members of the MPI for Psycholinguistics are researching the interrelationship between language, cognition and the conceptualization of space in various languages. Research results show that there are three frames of spatial reference, the absolute, the relative, and the intrinsic frame of reference. This study first presents results of this research in general and then discusses the results for Kilivila. Speakers of this Austronesian language prefer the intrinsic frame of reference for the location of objects with respect to each other in a given spatial configuration. But they prefer an absolute frame of reference system in referring to the spatial orientation of objects in a given spatial configuration. Moreover, the hypothesis is confirmed that languages seem to influence the choice and the kind of conceptual parameters their speakers use to solve non-verbal problems within the domain of space.

Der Bau der Wissenschaften ... schreitet nicht in der Weise fort, daß er sich auf einem festen, ein für alle Mal gesicherten Fundament erhebt, um dann immer höher zu steigen. Jeder Aufstieg zur Höhe verlangt vielmehr von uns auch die entgegengesetzte Leistung und die entgegengesetzte Blickrichtung. Mitten im Aufbau und Ausbau müssen wir auf das Fundament zurückblicken - müssen wir uns um jene "Tieferlegung der Fundamente" bemühen, die Hilbert einmal als das eigentliche Ziel aller theoretischen Wissenschaft bezeichnet hat. Wenn dies für die exakte Wissenschaft gilt, so gilt es in noch viel höherem Maße für die Geisteswissenschaften. ${ }^{1}$

Ernst Cassirer (1938:230) 


\section{Aims of the "Space Project" ${ }^{2}$ at the Max-Planck-Institute}

The central aim of the former Cognitive Anthropology Research Group, now the Language and Cognition Department of the Max-Planck-Institute for Psycholinguistics, has been to further research into the relationships between language, culture and cognition by conducting fieldwork on issues of common interest to anthropology, psychology, and linguistics (see Levinson 1992, 1996a; Senft: 1994a, 1995a). There are many important questions about the nature and extent of universal human intellectual endowments in various domains, for which there has been little reliable cross-cultural data so far. The goal of the department is to fill some of these gaps and to contribute to the development of more sophisticated theories about the relationship between learned and native abilities, about the contribution of culture to cognition, and about the nature and transmission of culture itself and its relation to social structure and process.

The discussion of questions like these has a rather long tradition, of course, with Kant, Herder, Humboldt, Boas, Sapir, and Whorf as its most prominent protagonists. As Brown and Levinson $(1993,1)$ point out, our department tries to investigate some of these questions on possible interdependencies between language, culture and cognition empirically via the following stratagem:

'(a) first, pick a conceptual domain; (b) second, find two or more languages which contrast in the semantic treatment of that domain (i.e., where very different semantic parameters are employed); (c) third, develop non-linguistic tasks which will behaviourally reveal the conceptual parameters utilized to solve them; (d) compare the linguistic and non-linguistic representation systems as revealed by (b) and (c), and assess whether there is any correlation between linguistic and non-linguistic codings in the same domain.'

The (first) conceptual domain we have been 'picking' is the domain of 'space'. Thus, our initial major goal of research was to investigate the conceptualization of space and spatial reference in a cross-cultural/cross-linguistic perspective (see Pederson et al. 1998).

\section{Methods to elicit verbal reference to space}

To do this, we had to develop methods to build a comparative data base through parallel field research in different languages and cultures. This data base should then serve us as a kind of 'natural laboratory' for testing and 
revising theories in psychology and theoretical linguistics. For the purposes pursued here I will only describe some of the many methods we developed for data elicitation (see Senft 1994a). All these methods make use of various sets of interactive 'games' which are used to elicit task-oriented verbal descriptions in native speakers of the language under study. Most of these tasks involve the recognition or the construction of spatial arrays from systematic sets of two- or three-dimensional stimuli.

The interactional games for focused linguistic elicitation were especially developed for our research purposes ${ }^{3}$ (see also Hill 1993). They all involve a 'director' consultant who is allowed to see a certain stimulus, and a 'matcher' who is not. The players are sitting side by side with a screen separating them so that they cannot see each other's stimuli. The orientation of the players is taken note of, and the field researcher instructs the players what to do in their own language - all instructions are standardized. Moreover, the field researcher encourages the players to interact verbally, especially if they think they have difficulties understanding each other. On the basis of the verbal descriptions given by the 'director' in the game, the 'matcher' is asked to reproduce threedimensional models involving familiar objects with intrinsic orientations, like a human statuette in various body poses and mini-landscapes inhabited by model farm animals, as well as unfamiliar and abstract objects. Some games also involve the matching of photographs on the basis of verbal descriptions; these photographs systematically cover certain spatial oppositions. All games are played at least three times with two consultants in two runs each. In the second run the matcher of the first run takes over the role of the director, and the director of the first run becomes the matcher. Figure 1 illustrates the basic idea of these games.

The interactional games that are relevant for this paper can be described as follows:

1. The 'photo-object-game' (or 'farm animals game') is played with threedimensional plastic toys and photos depicting a certain spatial configuration of these toys. The director describes the photo, and on the basis of this description the matcher uses the toys to rearrange the spatial configuration.

2. The 'wooden-man-game' requires that the director, on the basis of photos or on the basis of a wooden human statuette with flexible angles, describes certain body-poses. The matcher has to adjust his or her statuette in such a way that the resulting body pose matches the description. 


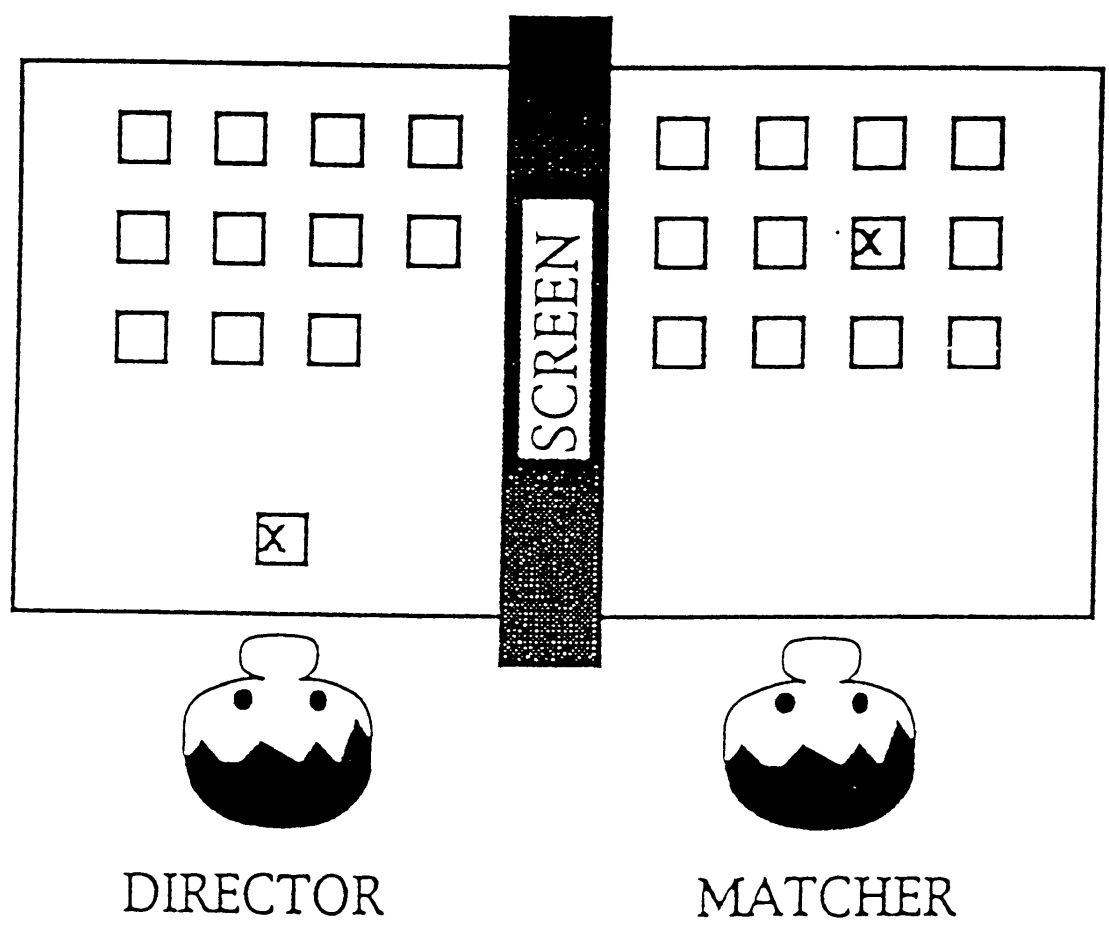

Figure 1.

3. In the 'Tinkertoy-games' the matcher - with the help of a building system for children - has to build a number of three-dimensional configurational and non-configurational constructions on the basis of the director's description which itself is based either on the same object or on a photo of the object to be constructed (see Senft: 1994b).

4. The 'photo-photo-game' consists of four series of $2 \times 12$ photographs; here the matcher has to select one photo on the basis of the director's description. The photos depict certain localizations and configurations of objects with and without intrinsic features (like men vs. trees and balls) in four directions on the horizontal plane (see Pederson: 1993, see also Figures 8, 9, and 12 below). Moreover, the set contains a number of distractor photos, so it did not become too obvious to the players what we were after with the game.

As already mentioned above, these four games were designed to elicit descriptions of spatial arrays and configurations. The next three games were developed 
to elicit the description of motion events and thus certain notions of motion. They consist of two route direction games and a film description task.

5. In the first 'route-description game' the director and matcher play with two dolls and two identical 'stylized' landscapes in front of them. These landscapes are organized symmetrically around a central axis, with objects on either side of the central axis being of identical shape and colour. This symmetry within the base design should force the consultants to differentiate directions in the crossaxis (the so-called left-right axis). The director is asked to let his/her doll walk and describe a route that is indicated by a small chain on his or her landscape so that the matcher can let a small doll 'walk' this route on his or her landscape. (see Weissenborn: 1986, Senft: 2000, also Wilkins, Hill: 1995).

6. The second route direction game, the 'maze task game' is quite similar to the first one. However, here the players do not use a 'stylized' landscape, but have to describe and move their dolls on a kind of map - a maze - in front of them. The route to be described is indicated again on the maze in front of the director by a chain (see Pederson, Senft 1996).

7. The 'ENTER/EXIT game' is just a description task. This game makes use of computerized animation trick film clips. ${ }^{4}$ The trick film consists of 13 movie clips which depict scenes in which a man is entering and exiting a house. A director has to look at the video clip (that is presented to him/her on the screen of a watchman) and then describe these scenes to a partner who does not see these clips.

So much for some of the methods we developed to elicit verbal reference to space. Right from the beginning of our research we were aware of the fact that these games have certain inbuilt restrictions and constraints with respect to what kind of data on spatial language is elicited with them - this was necessary for eliciting comparative data. However, we attempted to design these games so that they really elicit as broad a range as possible of the vocabulary for spatial reference to be found in the speech community under study. Moreover, it goes without saying that playing these games requires a certain familiarity of the researchers with their fields and with the languages they research and speak themselves. It is only on the basis of their experience and their competence in the languages under study that researchers can adequately use these games for linguistic elicitation, that they can give the instructions to their consultants and that they can decide whether or not the gathered data represent - at least in part - the everyday usage of these expressions for spatial reference or whether the elicited data have to be regarded as 'artefacts' of the elicitation method. 
With the above described methods of data gathering we elicited corpora of contextually anchored yet complex interactive texts that incorporate many examples of spatial language. This corpus constitutes our comparative data base for the research on verbal reference to space in different languages and cultures. In what follows I will briefly report on the general result of first analyses of these data.

\section{Frames of spatial reference}

First analyses of the data gathered in the languages researched by members of our project ${ }^{5}$ revealed fundamental differences in how these languages refer to space. For describing these differences we use an - at least at the moment somewhat simplified - typology of spatial systems or frames of spatial reference. This typology defines three such systems. We refer to them as 'relative', 'absolute', and 'intrinsic' (see Levinson 1996a:359, 365-373; 1996b; Senft: 1994a:419; see also Bühler 1934). They differ with respect to how angles are projected from the 'ground' (or 'relatum') in order to situate the location of the 'figure' (or 'theme') that is referred to (Talmy 1978:627; see also Klein 1991:78, Senft 1997: 10).

Relative systems are viewpoint-dependent: Localisations in space are derived from, and described on the basis of, the position and orientation of the speaker. In these systems a sentence like 'The ball is to the right of the man' is understood from the speaker's point of view only - i.e., this reference completely neglects the orientation of the man.

Absolute systems operate on absolute concepts of direction (which may be linear or defined by quadrants). They are based on conventionalized directions or other fixed bearings that can be derived from metereological, astronomical, or landscape features. In these systems (and in our data) we find sentences like e.g., 'The ball is to the west of the man/uphill from the man/seawards from the man.'

Intrinsic systems utilize inherent, intrinsic features of an object to derive a projected region or to anchor the spatial reference to an object in these features. In these systems a sentence like 'The ball is to the man's right.' is understood as follows: A man is an object with a front and back, a left and right side assigned to it. Thus, in intrinsic systems this sentence refers to the position of the ball on the basis of the orientation of the man - the ball is at the right side of the man, then - the orientation of the speaker does not play any role whatsoever and is — within this system — completely irrelevant for the understanding of this 
sentence. However, we want to note here that speakers using intrinsic systems for their spatial references also refer to the same configuration with the sentence we already mentioned above, namely: 'The ball is to the right of the man.' Thus, languages can be ambiguous with respect to whether they use an intrinsic or a relative perspective in their spatial references. Sentences like the last one presented can only be disambiguated in the actual situation and context.

All three systems can be found in a given language, and they can be utilized for spatial reference; however, many of the languages we have been studying so far frequently seem to prefer one frame of reference in a particular context.

Because of these observations we came up with the following hypothesis:

If speakers of a language preferentially use one reference system in a particular spatial domain, then these speakers will rely on a comparable coding system for memorizing spatial configurations and making inferences with respect to these spatial configurations in non-verbal problem solving.

To falsify or verify this hypothesis we developed a number of experiments to test the interrelationship between space and cognition. In what follows I briefly present these tests.

\section{Non-verbal experiments}

The next step in our research was to explore the cognitive implications of the three systems of verbal spatial reference. Relative (R), absolute (A), and intrinsic (I) systems differ with respect to their dependence $(+)$ or independence $(-)$

- with respect to the speaker's location and orientation,

$$
\mathrm{R}+\quad \mathrm{A}-\quad \mathrm{I}-
$$

- with respect to the rotation of the spatial configuration,

$$
\mathrm{R}+\mathrm{A}+\mathrm{I}-
$$

and

- with respect to the rotation of the ground

$$
\mathrm{R}-\quad \mathrm{A}-\mathrm{I}+\mathrm{C}
$$

Based on these differences of the three frames of spatial references we developed 5 different non-verbal experiment-like tests. These experiments for the investigation of non-verbal spatial cognition explore the nature of the spatial coding for memory and inference, and make it possible to determine whether this non-verbal 
coding has certain specific properties. These properties can then be compared to the verbal codings elicited by the first kit to see whether there is a correlation between the verbal and the non-verbal systems of spatial coding (see Danziger: 1993; also Senft 1994a:420-427).

I will only very briefly describe these experiments and the considerations they are based on here (for detailed descriptions see Brown, Levinson: 1993; Danziger: 1993; Senft: 1994a). First I want to mention that all the five tasks attempt to investigate the opposition between two different coding systems of space, namely between what we call the 'relative' coding system or frame of reference that uses expressions like 'left/right/front/back' for spatial references and the 'absolute' system or frame of reference that uses expressions like 'north/south/east/west, uphill/downhill, seawards/landwards, upriver/ downriver', etc., for spatial references. All five tasks within this kit have the same fundamental design. The consultants are shown a stimulus on one table (Table 1) and are instructed to memorize what they have seen. After a short delay they are rotated 180 degrees and led across to another table (Table 2) at a certain distance which faces in the opposite direction from Table 1. The consultants are now asked to reconstruct the same array, or to select the same array from a set provided. The stimulus arrays are so designed that they have either a left/right or a front/back asymmetry when viewed on Table 1.

To give an illustrative example (see Brown, Levinson: 1993, 8): Suppose the consultants see an arrow on Table 1 that is pointing from their point of view to the right. After a short pause and after having been turned $180^{\circ}$ they are led to Table 2. There they find two arrows; again, from their point of view one arrow is pointing to the right and the other arrow is pointing to the left. The consultants are asked now to chose the arrow that resembles the one they just saw half a minute ago on Table 1. Consultants who memorized the orientation of the arrow on Table 1 on the basis of a relative system of spatial coding will select at Table 2 the arrow that - from their point of view — is also pointing to the right - here the fact that standing in front of Table 2 the consultants have turned $180^{\circ}$ is of crucial importance. Consultants, however, that use an absolute system of spatial coding memorize the fact that the arrow on Table 1 pointed, e.g., towards north - they will then select the arrow which is also pointing towards this direction at Table 2, completely independent of the fact that they have turned $180^{\circ}$ (see Figure 2).

The first experiment — 'animals in a row' — tests recall memory for spatial configurations (see Figure 3). Subjects look at 3 animals in a row, should concentrate on the relative order of animals, are then twisted $180^{\circ}$ and asked to 
Table 1

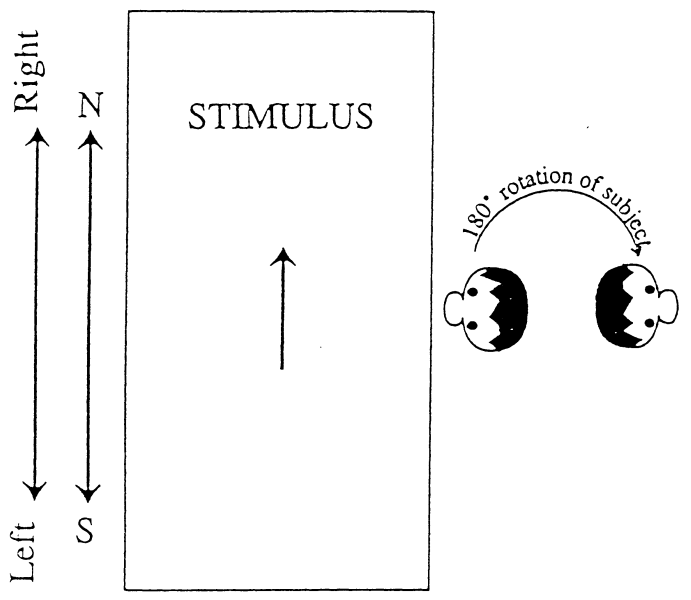

Table 2

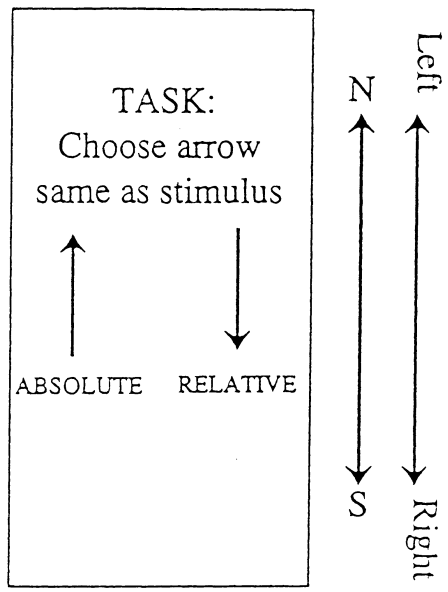

Figure 2.

remake the same assemblage. The experimenter, however, is really only interested in the alignment direction.

The second experiment — 'red and blue mazes' — tests recall and recognition memory for spatial configurations (see Figure 4). This test uses 5 identical

Table 1

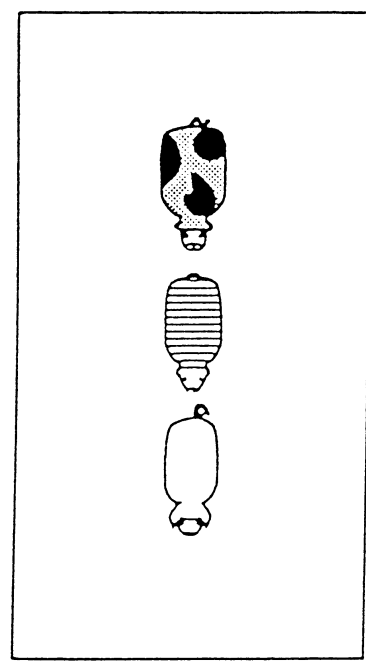

Table 2

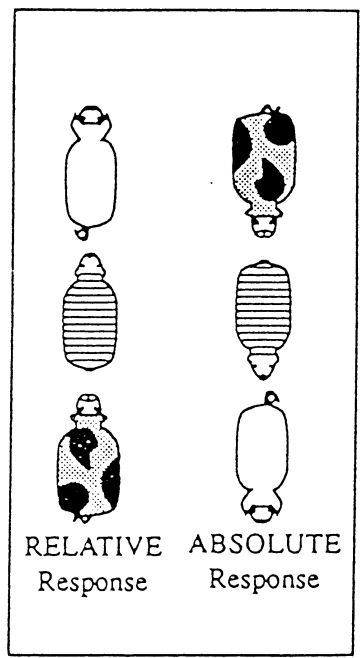

Figure 3. "Animals in a row game" 
Table 1

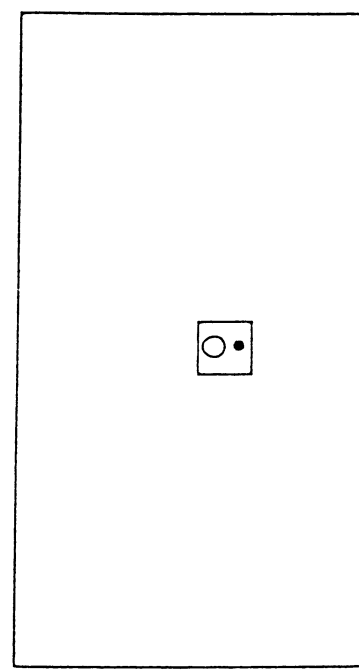

Table 2

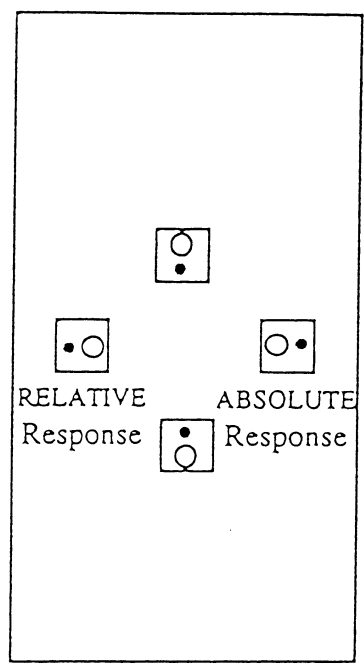

Figure 4. "Red and blue mazes game"

cards with 2 differently colored circles of different size. Subjects look at a card and should concentrate on the orientation of the circles, are then turned $180^{\circ}$ and are asked to select the card with the same orientation of the circles from among 4 choices of identical, but differently oriented cards.

The third experiment — 'man and paths' (or 'motion maze task') — tests recall and recognition memory with respect to movement in space and the transformation of movement into the construction of a path (see Figure 5). The test consists of a figure resembling a little man and a maze. Subjects look at the little man being walked by the experimenter in a certain complex path and should remember this path; they are then turned $180^{\circ}$ and are asked to select the endpoint on a maze where the little man would end up if he had followed that path and not others on the maze.

The fourth experiment — 'the scout game' (or 'completed path task') — tests the ability to finish an incomplete path and recognition memory (see Figure 6). It consists of 5 separate maps with 3 cards - a distractor with a path that does not complete the path seen on the map, a card with a path that is chosen in an absolute response and a card with a path that is chosen in a relative response. Subjects have to look at the map, memorize it, then rotate $180^{\circ}$ and are asked to choose one of the three cards that will finish the incomplete path seen on the map. 
Table 1

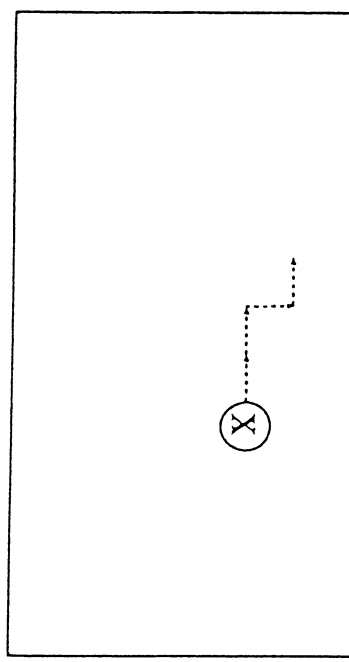

Table 2

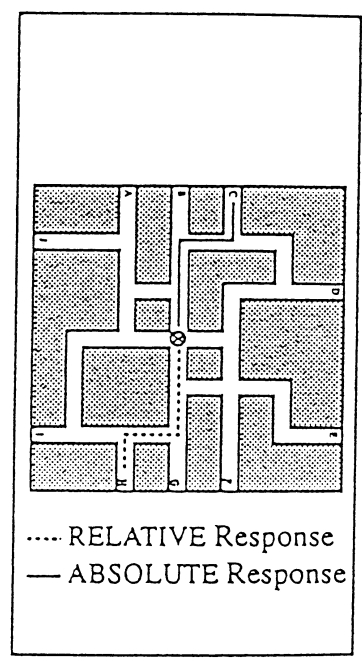

Figure 5. "Man and paths game"

Table 1

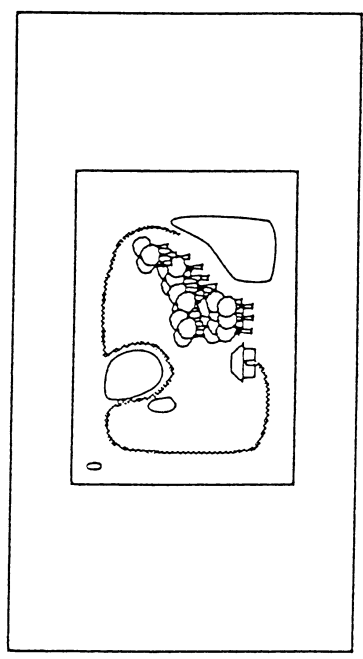

Table 2

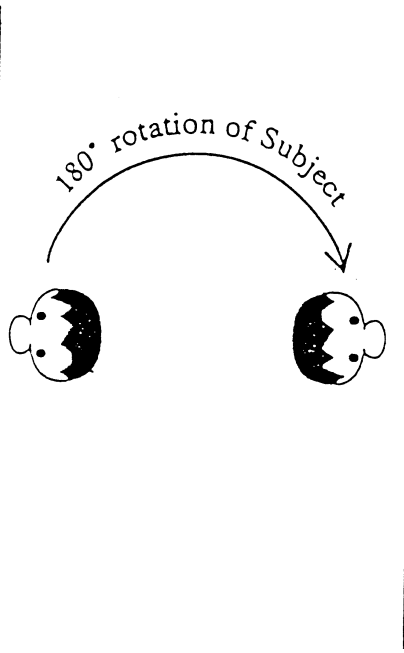

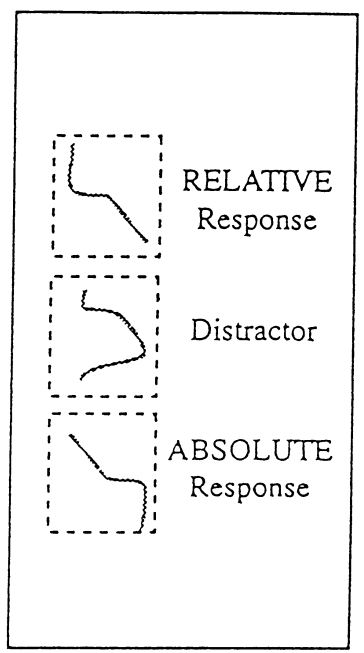

Figure 6. "The scout game" 
The fifth experiment — 'the transitivity task' (or 'transitive inference') — tests the ability to make transitive inferences (see Figure 7). Subjects look at a relationship between the two objects $\mathrm{A}$ and $\mathrm{B}$ on one table and remember it; then they turn around $180^{\circ}$ and go to another table where they look at a relationship of the two objects $\mathrm{B}$ and $\mathrm{C}$ and remember it; then subjects turn around $180^{\circ}$ again and go to the first table; there they see object A - and they have to specify which side of $A$ object $C$ could be located by transitive reasoning.

\section{Language, cognition and conceptions of space: First results}

First, though still rather impressionistic and quick, analyses of the elicited verbal data revealed which systems of spatial reference were to be found in the languages researched and which systems were preferentially used by the speakers of these languages. Based on these very first results and with our general hypothesis in mind we made predictions with respect to which results could be expected in the non-verbal cognitive tasks for the various speech communities. Table 1 (see Senft 1995a:170) summarizes these predictions and presents the results we actually observed in analyzing the subjects' behaviour in the non-verbal tasks:

This table shows that — with the exception of Kilivila — our hypothesis with respect to the interrelationship between verbal and non-verbal coding of spatial configurations is verified. It seems that languages indeed do influence the choice and the kind of conceptual parameters their speakers use to solve certain non-verbal problems within the domain 'space', to memorize certain spatial configurations, and to represent them in their long-term memory.

\section{A problematic case}

As the researcher who studied the only language that did not seem to verify our hypothesis I was, of course, somewhat puzzled. My puzzlement became even stronger when we looked more closely at the results of one of the 'photo-photo matching games', the 'man and tree game' that was developed to elicit verbal spatial reference to relationships in the horizontal plane between two unfeatured objects (red balls) and between a featured object (a man) and a nonfeatured object (a tree). ${ }^{6}$ Developing this game it was decided to arrange 'the man' and 'the tree' (see Figure 8) in such a way that from the observer's point 


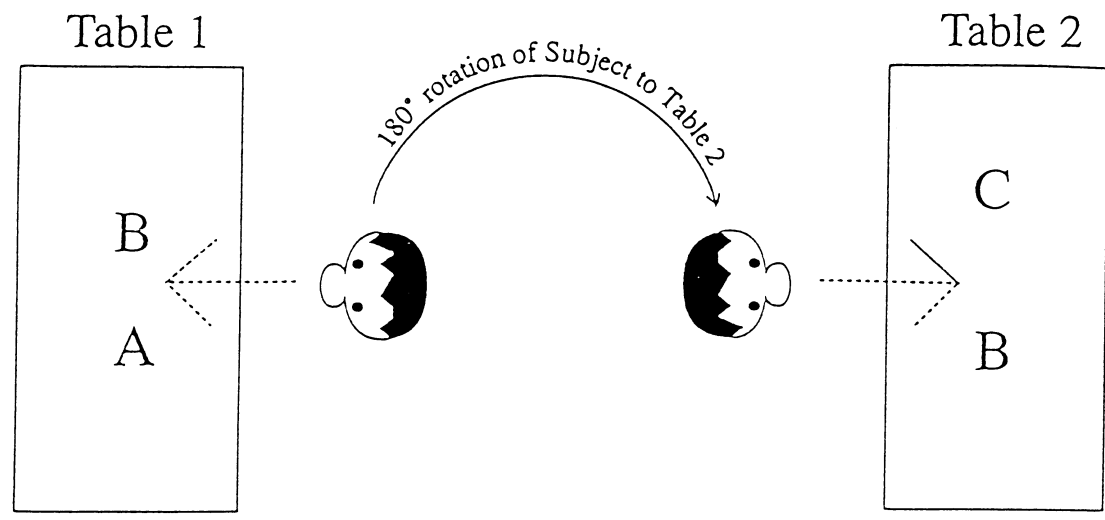

Table 1

TASK:

Place C

A

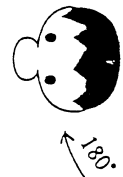

Table 1

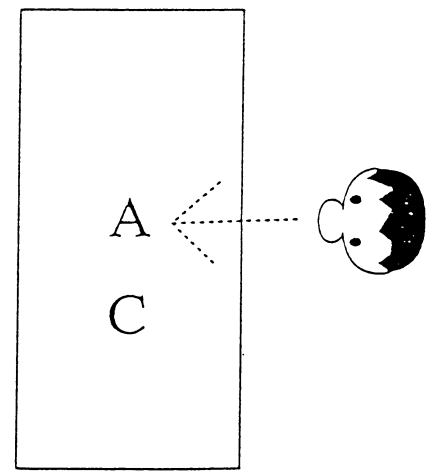

RELATIVE

Table 1

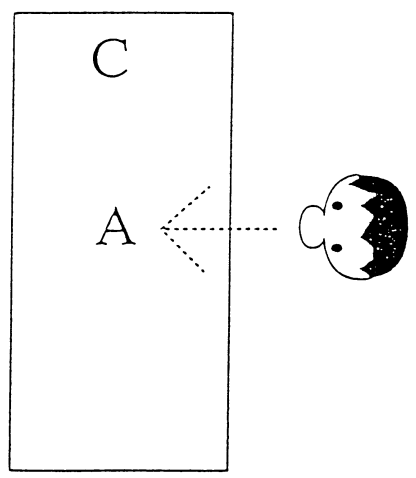

ABSOLUTE

Figure 7. The "transitivity task" 
2.3

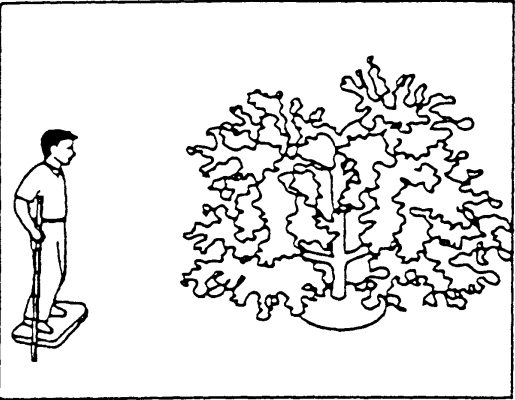

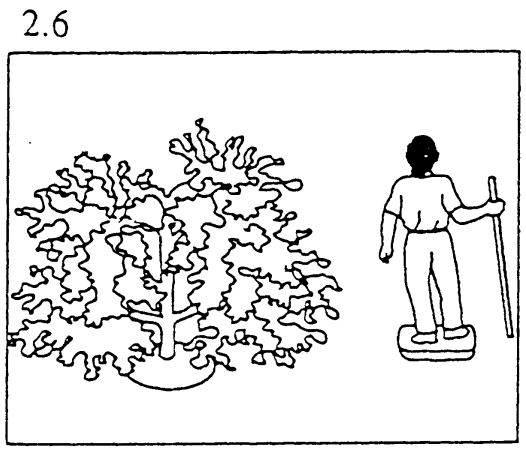

2.7

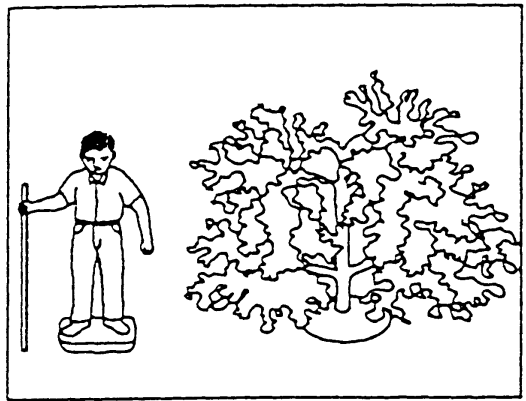

2.4

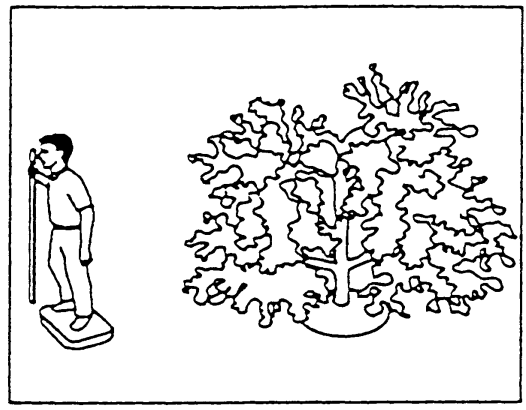

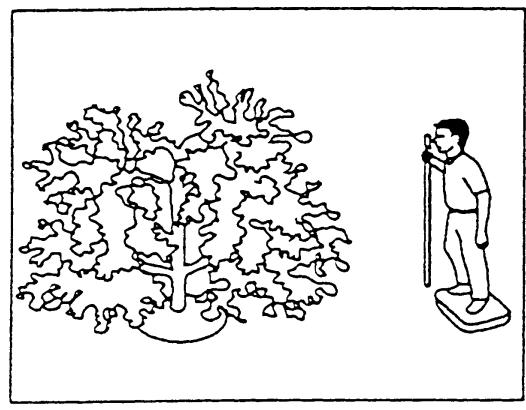

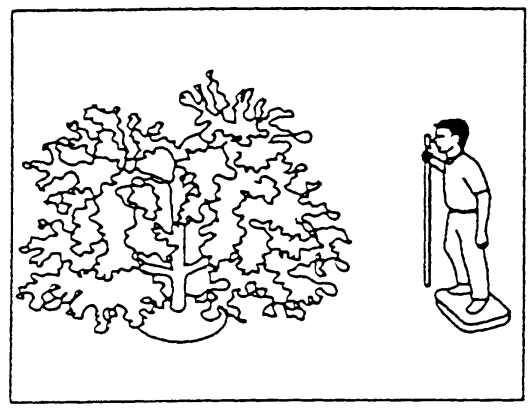

2.5

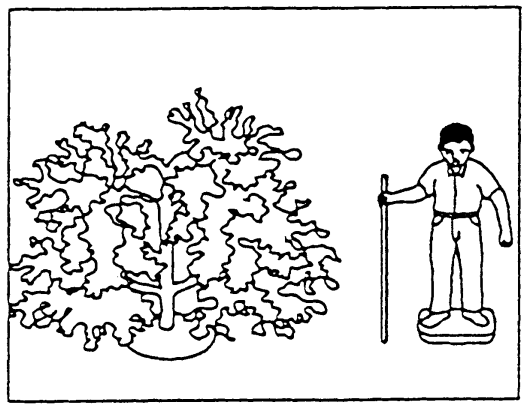

Figure 8. Drawings of "Man and tree" photographs 
Table 1. Verbal and non-verbal codification of spatial configurations

\begin{tabular}{llll}
\hline language & $\begin{array}{l}\text { preferred system(s) } \\
\text { of verbal codification }\end{array}$ & \multicolumn{2}{l}{$\begin{array}{l}\text { system(s) of non-verbal } \\
\text { codification }\end{array}$} \\
\cline { 3 - 4 } & & predicted & found \\
\hline Arrernte & $\mathrm{A}$ & $\mathrm{A}$ & most A \\
Hai//om & $\mathrm{A},(\mathrm{I})$ & $\mathrm{A}$ & most A \\
Tzeltal & $\mathrm{A}$ & $\mathrm{A}$ & $\mathrm{A}$ \\
Longgu & $\mathrm{A}$ & $\mathrm{A}$ & $\mathrm{A}$, also R \\
\hline Dutch & $\mathrm{R}$ & $\mathrm{R}$ & $\mathrm{R}$ \\
Japanese & $\mathrm{R}$ & $\mathrm{R}$ & $\mathrm{R}$, also A \\
Kilivila & $\mathrm{I}, \mathrm{R}$ & $\mathrm{R}$ & $\mathrm{A}$, also R \\
\hline Belhara & $\mathrm{A}$ & $\mathrm{A}$ & most A \\
Tamil (rural) & $\mathrm{A}$ & $\mathrm{A}$ & $\mathrm{A}$ \\
Tamil (city) & $\mathrm{R}$ & $\mathrm{R}$ & $\mathrm{R}$ \\
Kgalagadi & $\mathrm{R}(\mathrm{A}, \mathrm{I})$ & $\mathrm{R}$ & $\mathrm{R}$, also A \\
\hline Mopan & $\mathrm{I}$ & ad hoc & $\mathrm{R}, \mathrm{A}$ \\
Totonac & $\mathrm{I}$ & ad hoc & $\mathrm{R}, \mathrm{A}$ \\
\hline
\end{tabular}

A $=$ absolute reference system

$\mathrm{R}=$ relative reference system

$\mathrm{I}=$ intrinsic reference system

of view in three photos (2.3., 2.4., and 2.7.) 'the man' was standing on the left and 'the tree' was standing on the right side of the photo, while in another three photos (2.5., 2.6., and 2.8.) 'the man'was standing on the right and 'the tree' was standing on the left side of the photo. These photos also included two 'mirror image' pairs (photos 2.3. and 2.5. and photos 2.7. and 2.8.). For the analysis of the speakers' behaviour with respect to this task we abstracted from the actual verbal utterances and extracted propositions from the data that conveyed 'standing' and 'facing' information that were relevant for describing the spatial relationship between the objects in this game. The target set of photos presented the following different configurations of the 'man' and the 'tree':

In our corpora we find utterances like the following Kilivila one: ${ }^{7}$

photo described: 2.8 -photo selected: 2.8

kwe-yuvela te-ta tomwotala-bani kai o

CP.thing-again CP.man-one person 1.PAST-find tree LOC 


\section{kakata kaitukwa wa e mata-la e-semwa}

right walking.stick only and eye-his 3-come.towards.speaker

'A thing again, one person I found, (a) tree at (his) right, a walking stick only, and his eyes look at me.'

From such an utterance we extracted the following propositions:

- tree at (man's) right (='standing information')

- man's eyes look at me (='facing information')

The distinguishing propositions allowed the speakers to select the respective photos in this game. The propositions that were extracted from the data were formulated and summarized in English (which served us as a kind of metalanguage). Propositions that distinguished the exact subgroup of pictures from the rest of the picture stimuli were defined as being 'functionally equivalent'. Thus in Arrernte the propositions 'tree facing west' and 'man standing in east' (or, more precisely, the Arrernte linguistic forms within which these propositions are embedded and uttered in an adequate context) are functionally equivalent because they would identify the photos $2.3,2.4$, and 2.7 together as a subgroup as opposed to the photos 2.5., 2.6., and 2.8 (where the propositions 'tree facing east' and 'man standing in the west' would hold - in the adequate context, of course). For Kilivila, as well as for Mopan, no such functional equivalent propositions could be found. Speakers of both languages preferred the intrinsic reference system for their descriptions of the spatial arrangements depicted in the photos of this task and we observed the highest percentage of mismatches with respect to which photo was described by the director and which photo was selected by the matcher on the basis of this description. Thus speakers of Kilivila (and Mopan) showed rather 'poor' results with respect to solving the spatial problems they were confronted with in this specific task (see Pederson et al. 1998). However, a closer look at the Kilivila data revealed a number of instances where mistakes of the following kind were made:

The director gave an unequivocal description of a photo (here photo 2.6):

la-bani te-tala tau la kaitukwa o

1.PAST-find CP.man-one man his walking.stick LOC

kakatae kai o la kikivamae tubulo-la

right and tree Loc his left and back-his

e-mikeya-gu

3-come-towards-me

'I found one man (with) his walking stick at the right and (a) tree at his left, and his back points towards me.' 
Despite the director's unequivocal description of photo 2.6. - the proposition: 'man's back towards me' clearly distinguishes photo 2.6 from photo 2.4 - the matcher decided to select photo 2.4. on the basis of this description. After the director had described photo 2.6 adequately, he obviously saw no more need later to specify photo 2.4 more clearly than he did:

E te-tala tau kai o tubulo-lae kaitukwa e-yosi

And CP.man-one man tree Loc back-his and walking.stick 3-hold

o kakata

LOC right

in right

'And one man, (a) tree at his back, and he is holding a walking stick in his right.'

However, his 'underspecification' of this photo - a player may have the impression that the tree in the photos 2.7 and 2.8 are also somewhat behind the man - made the matcher now choose photo 2.6 instead of photo 2.4. Moreover, we also find many descriptions of photos in Kilivila that are clearly semantically underspecified, but the matcher chose the right photo just by chance.

Problems like these force us to look critically back at the design of this task for eliciting verbal spatial reference in small-scale face to face speech communities with unwritten languages in traditional cultures.

The 'man and tree' photo-photo matching task was the first 'space game' I played with my consultants on the Trobriands (I collected data with the four different series of the 'photo-photo game' (see above) from August 3rd to August 10th, 1992). This kind of elicitation situation was completely new for my consultants - I had never before used any comparable device for eliciting linguistic data in Kilivila. It may well be that the stunning new situation with these absolutely unknown elicitation materials detracted my consultants' concentration or otherwise influenced them in a negative way with respect to their performance. It is certainly not an everyday activity for Trobriand Islanders who rather rarely deal with photographs (except with those they get either from tourists or from me) to scan 12 pictures, a subset of which depict rather subtle differences with respect to the spatial configuration and orientation of objects like a plastic tree and a small plastic toy figure. Thus it is quite understandable, I think, to assume that the matchers decided for a picture as soon as they thought their choice would more or less match the directors' description. Moreover, I also assume that the directors did not monitor all the photographs from the very beginning of this game and that they were not aware of the fact 
that they really had to follow my instructions and be as exact and as exhaustive as possible in their descriptions. However, these considerations just refer to only a few of many uncontrollable parameters for the field researcher in such an elicitation situation. This argumentation implies, of course, self-criticism with respect to our methodology for data elicitation. It especially questions the adequacy of the elicitation tool used, i.e. the photographs developed for the 'photo-photo games'. It may well be that these photographs as elicitation tools are much too abstract (see Nüse 1996:91f.) and probably too Eurocentric in their sophisticated depiction of subtle spatial relationships and thus prove inadequate for eliciting verbal data in small-scale face to face speech communities like the community represented by the Trobriand Islanders in the village Tauwema. I am absolutely aware of the fact that this is a general problem for linguistic data elicitation in all language communities (see Senft 1995b), but I would also like to note here that especially in research projects with a comparative orientation it is extremely difficult to create elicitation devices that can be used in many speech communitites that are quite different from one another. I will come back to this topic below.

However, there is another problem I have in connection with the 'man and tree photo-photo matching game'. Although my research on Kilivila spatial reference has shown that Kilivila offers its speakers all three systems for spatial reference, all speakers preferred to use the intrinsic frame of reference, especially the use of intrinsic 'left' and 'right' in the 'man and tree' game. But if I look at the actual utterances produced in this game - leaving the level of abstractions we created by relying on 'translations' of these utterances into spatial propositions - I observe the following: It is quite clear that my consultants in the 'man and tree' game prefer the intrinsic frame of reference - in referring to the location of the objects in relation to each other. However, we also find the use of deixis for describing the orientation of the objects depicted in these photographs. In the two descriptions quoted above the Kilivila speakers make use deixis in the utterance '...e matala esemwa' - '... and his eyes look at me' (for photo 2.8.) and in the utterance '... e tubulola emikeyagu' - '... and his back points towards me' to describe the orientation of the man depicted in the photo with respect to the speaker. And in the following example the director uses the 'tree' within the picture (2.5.) as a kind of 'landmark' for describing the orientation of 'the man': 
kai ma-ke-na e-tota omata-la kaitukwa

tree DEM-CP.wood-DEM 3-stand in.front.of-him walking.stick

o la kakata e-to'ila mata-la e-seki

Loc his right 3-get.up.turn.round eye-his 3-give

ma-ke-na kai

DEM-CP.wood-DEM tree

This tree is standing in front of him, the walking-stick (is) in his right, he is getting up, turning round and his eyes look at this tree.

I concede that with this example one can argue whether or not the 'tree' in this description can be regarded as a kind of 'ad-hoc' landmark that could be part of an absolute system of spatial reference. However, many utterances in other photo-photo matching games show that Kilivila speakers refer to such ad-hoc landmarks when they refer to the orientation of the objects depicted in these photographs. I will illustrate this with the following example (taken from the photo series 3 that presents spatial relationships in the horizontal plane using featured objects that are facing in the same direction; the director was Gayoboda ( $\mathrm{G}$, male, approx. 28 years old), and the matcher was Yau (Y, male approx. 29 years old); see Figure 9):

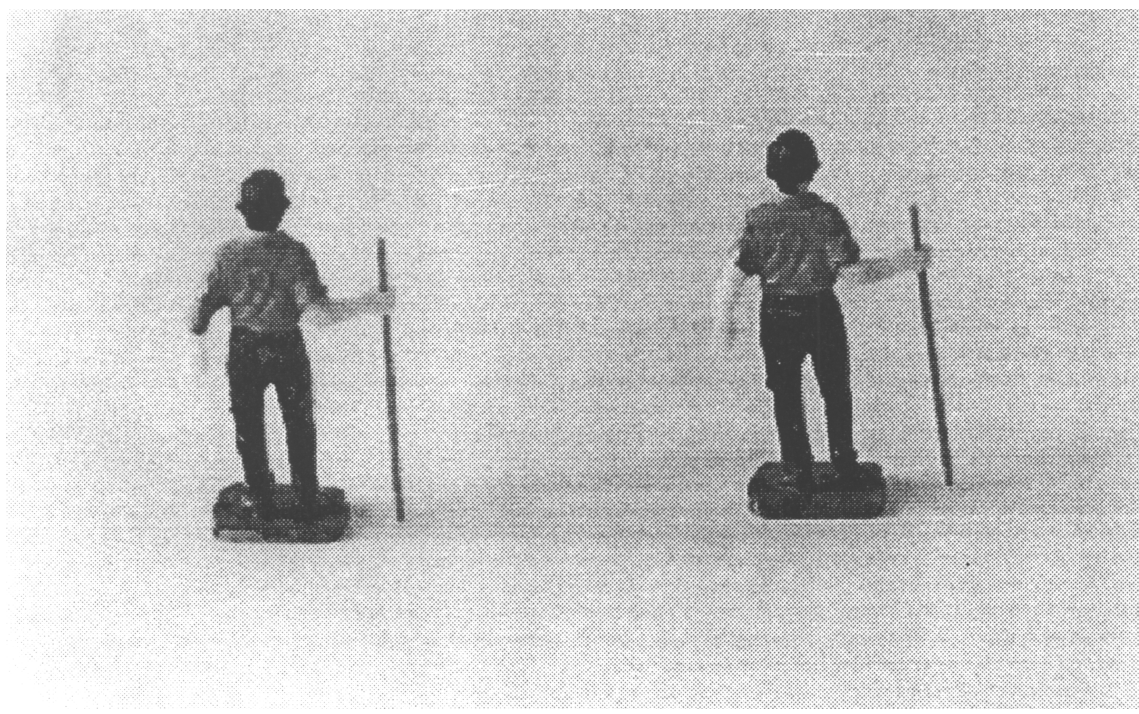

Figure 9. 
G.:

so la-nagi te-yu tauwau mata-si

friend 1.PAST-choose cP.man-two men eyes-their

e-la o bwalitasi kaitukwa o kakata

3-go LOC sea their walking.sticks Loc right

'My friend, I chose two men, they look towards the sea, their walking sticks (are) at the right.'

Y.:

e-tovadulu-si kena e-tobeya-si

3-stand.in.line/away.axis-PL or 3-stand.in.line/across.axis-PL

'They are standing in line on the away axis or they are standing in line on the across axis?'

G.:

e-tobeya-si e-tobeya-si

3-stand.in.line/across.axis-PL 3-stand.in.line/across.axis-PL

'They are standing in line on the across axis, they are standing in line on the across axis.'

Here the director $(G)$ refers to the fact that the men (in photograph 3.7.) look towards the sea - and the sea-land-axis (or rather sea/shore-bush-axis) is certainly an axis of an absolute (ad-hoc) landmark system. On the basis of this observation the interpretation of the spatial reference to the tree as a landmark reference in the preceding example becomes somewhat more plausible.

With these brief remarks I hope to have shown that - at least for Kilivila - the 'man and tree photo-photo matching game' was not an ideal stimulus for eliciting data to be used for generalizations with respect to language specific frames for spatial reference and their preferred usage. Moreover, I am rather hesitant to accept any such generalizations (not only with respect to Kilivila) if they are only based on the performance of three dyads of players producing verbal spatial references within the framework of just one specific and probably also rather Eurocentric elicitation task. If we want to come up with such generalizations we have to base them on much more sound empirical evidence - we have to look more carefully at the whole range of data we have been collecting so far. We just have to probe deeper. From the abstract, broad and general macro-perspective we have to zoom in on the micro-perspective and look much more carefully at the 'real things' we found, the broad corpora of rich empirical data. In what follows I want to sketch how such a procedure may look like for Kilivila - the language that seemed to be such a 'problematic case' for our typological analyses so far. 


\section{Frames of spatial reference in Kilivila}

In this section I will present, and comment on some Kilivila data that I gathered with 5 of the 7 interactional games described in Section 2 above. ${ }^{8}$ I will start with some observations that I made looking at data elicited in the 'photo-object game'. These observations will result in a reformulation of our central hypothesis with respect to the preferred usage of certain frames of reference within languages. Then further data will be presented to illustrate and justify this reformulation - and finally it will be shown that with this reformulated hypothesis the puzzle with respect to Kivila and its preferred systems of verbal and non-verbal codification presented in Table 1 at the end of Section 5 above can be solved easily.

With the 'photo-object game' I elicited descriptions like the following one (with Toyogima (T, male, approx. 26 years old) as the director and Dodom (D, male, approx. 33 years old) as the matcher on June 22nd, 1993, see Figure 10):

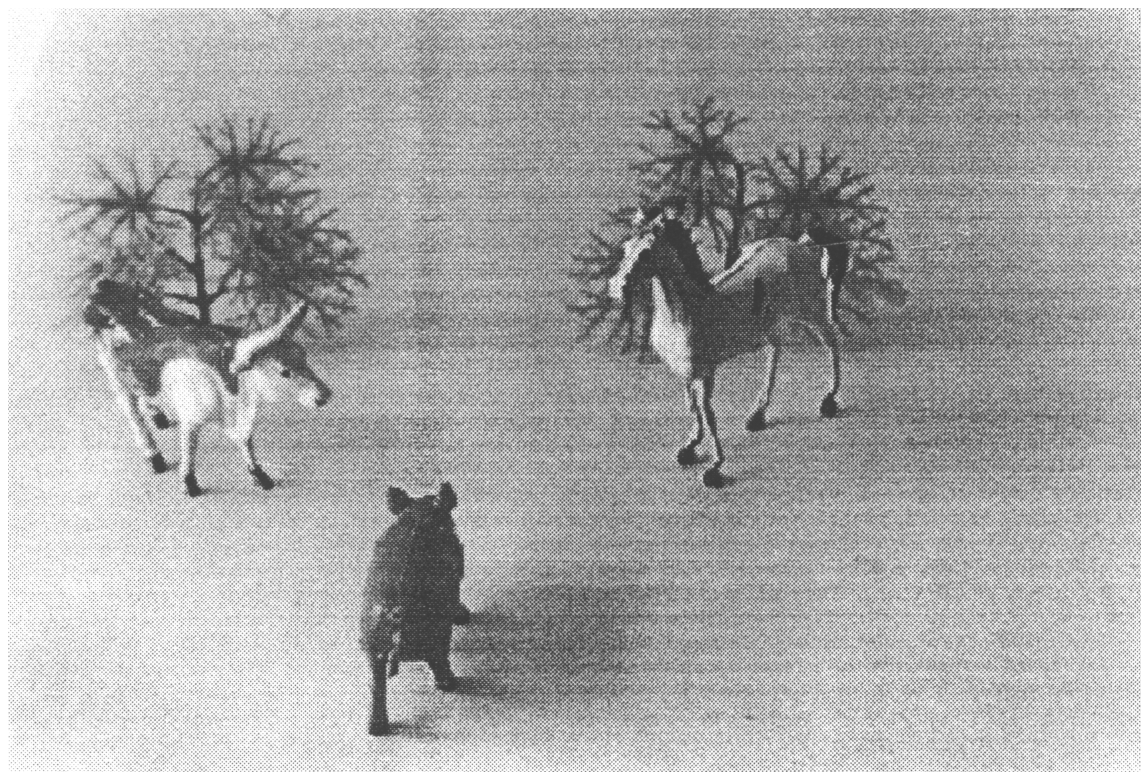

Figure 10. 
photo-object game, photo-No: 4

$\mathrm{T}$ :

Ma-na-na bulumakau o pilakeva e-tota mata-la DEM-CP.animal-DEM cow LOC topside 3-stand eye-its

'This cow is standing at the topside, its eye'

e-la o valu poa-la e-seki Tuyabwau e

3-go Loc village back-its 3-be Tuyabwau.well and

'goes towards the village, its back is towards the Tuyabwau well, and'

ke-ta kai ma-na-na bulumakau o kopo'u-la

CP.wood-one tree DEM-CP.animal-DEM cow LOC behind-it

'a tree, this cow behind it'

e-tota, o tubolo-la bogwa oku-nukwali. E

3-stand Loc back-its already 2-know and

'it is standing, at its back, you know already. And'

e-mweki ma-na-na osa o kwadevabogwa

3-come.straight.to DEM-CP.animal-DEM horse LOC beach already

'it comes straight to, this horse, to the beach, already'

makala wala, mata-la e-la o laodila poa-la

like only eye-its 3-go Loc bush back-its

'like (this), well, its eye goes to the bush, its back'

e-seki Tuyabwau e kai o kopo'u-la. E

3-be Tuyabwau-well and tree Loc behind-it and

'is to the Tuyabwau well, and a tree is behind it. And'

bunukwa navivila bunukwa navivila o mata-si

pig female pig female Loc eyes-their

'a sow, a sow in front of their eyes'

e-tota

3-stand.

'it is standing (there).'

$\mathrm{T}$ : 'The cow is standing at the topside, it looks towards the village and its back is towards the Tuyabwau well, and a tree is standing behind it, at its back, you know. And this horse comes straight to the beach(side), it looks to the bush and its back is towards the Tuyabwau well, and a tree is standing behind it. And a sow, a sow is in front of their eyes'.

photo-object game, photo-No: 15 (see Figure 11) 


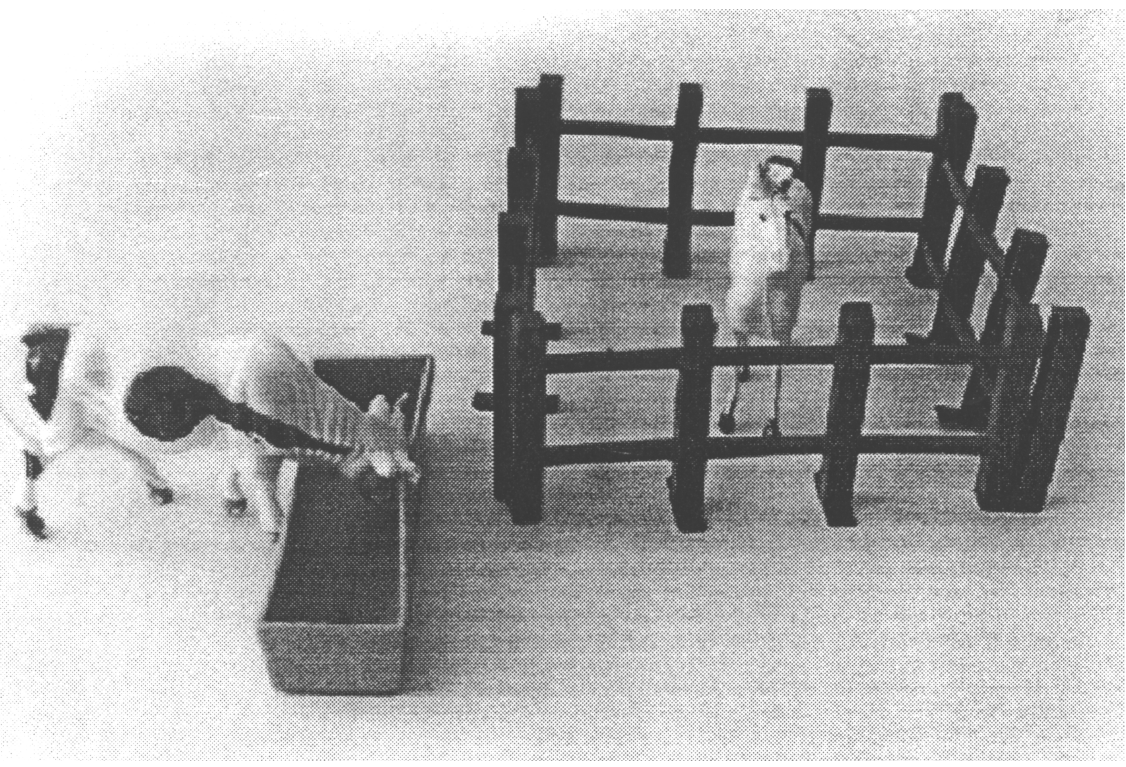

Figure 11 .

$\mathrm{T}$ :

Amyaga buku-vagi kali

What's.the.name 2.FuT-make fence

'What's the name, you will make a fence'

ke-vasi e-vekeyao bwalitae ma-na-na

CP.wood-four 3-go to LOC sea and DEM-CP.animal-DEM

'(with) four wooden (pieces) it goes (points) to to the sea and this'

osa ma-na-na osa oluvale-la e-tota poa-la

horse DEM-CP.animal-DEM horse inside-it 3-stand back-it

'horse, this horse, it is standing inside (of) it, it stands, its back'

e-la Tuyabwau mata-la e-la o valu.

3.go Tuyabwau.well eye-its 3-go Loc village

'goes (to the) Tuyabwau (fresh-water well), its eyes go to (the) village.'

E ma-na-na bulumakau o kepapa-lavavagi

and DEM-CP.animal-DEM COW LOC side-its thing

'And this cow at the side of the thing,'

ma-na-kwa kali e-tota poa-la e-la o laodila

DEM-DEM-CP.thing fence 3-stand back-its 3-go LOC bush

'this fence it is standing, its back goes to the bush' 
mata-la e-mwa o kwadeva e-kululu e-kamkwam

eye-its 3-come to Loc shore 3-look.down 3-eat

'its eyes come to the shore, it looks down, it eats,'

e-mumum ala ti.

3-drink its tea

'it drinks its tea.'

D:

E ma-na-na osa ambe e-sisu?

and DEM-CP.animal-DEM horse where 3-be

'And this horse, where is it?'

$\mathrm{T}$ :

Oluvale-la kali.

inside-its fence

'Inside its fence.'

D:

Mata-la ambe bi-mwa?

eye-its where 3.FUT-come.to

'And its eye, where will it come to?'

T:

Bi-la o valu.

3.FUT-go LOC village.

'It will go to the village.'

T: 'Well, what's the name, you build a fence with four pieces so that it points to the sea, and this horse, this horse, it is standing inside this fence, its back points in the direction of the Tuyabwau-well, and it looks towards the village. And this cow is standing at the side of this thing, this fence, with its back towards the bush and it looks towards the shore, it is looking down, it is eating and it is drinking its tea'.

D: 'And where is this horse?'

$\mathrm{T}$ : 'Inside the fence'.

D: 'And where does it look towards?'

T: 'It looks towards the village'.

Within these verbal interactions we observe the following: The director relies on the intrinsic frame of reference in order to locate objects in relation to each other. This is nicely illustrated in the description of photograph 4 quoted above. Here the expressions ' $o$ kopo'ula (behind it), o tubolola (at its back), $o$ matasi (in front of their eyes)' clearly mark the intrinsic frame of reference the 
speaker uses for describing the location of the objects in relation to each other. In both descriptions we also immediately notice the use of ad-hoc landmarks like 'laodila (bush), kwadeva (beach), bwalita (sea), valu (village), Tuyabwau (name of a fresh water well), pilakeva (topside, landside - vs 'pilitinava' = lowland, seaside, beachside)' - generally in connection with the locative ' $o$ '; thus Kilivila speakers switch to an absolute frame of reference that uses ad-hoc landmarks to describe the orientation of the objects depicted in the photographs. Among these ad-hoc landmarks we not only find names of wells, beaches, reefs, rocks, or trees, but also - depending on the context and situation, of course - references to houses and their respective owners and even to people that are sitting in the respective direction. These axes of orientation are indeed created on the spot in a very much ad-hoc like manner, and they may refer to landmarks both within a big and a small scale environment, like for example the general environment or marks on the set of the space-games. All these axes are used as frequently as the bush-sea or bushshore axis and therefore I would rather not assign a special status to the latter axis - although this land-sea axis features rather prominently in many other (and not only Austronesian) languages (see Senft 1997). To summarize once more: Kilivila speakers prefer the use of the intrinsic frame of reference for the location of objects in relation to each other ${ }^{9}$ and they prefer an ad-hoc landmark absolute frame of reference for describing the orientation of these objects. On the basis of this finding we have to reformulate our basic hypothesis (presented at the end of Section 3 above) so that it becomes more explicit. We can no longer state that languages seem to prefer one frame of reference in a particular context - without specifying for what means and ends speakers of these languages use these preferred systems. We have to consider functional aspects of frames of reference. Thus, I propose to reformulate our hypotheses with respect to the preferential usage of the spatial frames of reference described in Section 3 above as follows:

The relative, instrinsic, and absolute frames of reference can all be found and can be utilized for verbal spatial references in a given language. However, languages seem to prefer certain frames of reference in particular contexts that ask for different spatial tasks and that may require different means and ends of spatial reference, like, for example, expressing the location of objects with respect to each other, and/or with respect to the space and the spatial configuration in which the speaker and hearer are in relation to these objects, and/or expressing the orientation of these objects in space. Thus different means and tasks within the realm of 
spatial reference may evoke the preferred use of similarly different frames of reference in a given language.

This reformulated hypothesis covers the facts of spatial reference that are to be observed in Kilivila - as the following examples illustrate. Let us first look at two more examples from the 'photo-photo' matching games (besides the example from the 'man and tree' game presented in Section 6 above). In the game that was devised to elicit references with respect to the spatial relationship of featured objects on the horizontal plane oriented towards the same direction speakers typically produced descriptions like the following one (see Figure 9):

$$
\begin{aligned}
& \text { m-to-si-na te-yu tauwau e-yosi-si } \\
& \text { this-CP.man-PL-this CP.man-two men 3-hold-PL } \\
& \text { si ketukwa mata-si e-la o bwalita. } \\
& \text { their walking.stick eye-their 3-go Loc sea }
\end{aligned}
$$

'These two men are holding their walking sticks, they look towards the sea'.

In the game that was devised to elicit references with respect to the spatial relationship of featured objects on the horizontal plane in different orientation speakers typically produced descriptions like the following one (see Figure 12):

Figure 12. 
la-gisi te-yu tauwaute-ta mata-la e-la

3.PAST-see CP.man-two men CP.man-one eye-his 3-go

Tuyabwau te-ta mata-la e-ma o valu

Tuyabwau.well cP.man-one eye-his 3-come Loc village

kepapa-la so-la kepapa-la so-la.

side-his friend-his side-his friend-his

'I saw two men, one is looking towards the Tuyabwau fresh water well, one is looking towards the village, (and they are standing) side by side.'

Again we note the absolute ad-hoc local landmark system that is used to describe the different orientation of the two objects depicted in the photographs, and (in the second example) we also observe again the use of the intrinsic frame of reference to express the spatial relationship the two (featured) objects depicted in the photograph have with respect to each other.

The following rather typical examples illustrate some acts of spatial reference elicited in playing the 'route description game': ${ }^{10}$

m-to-na tau e-tota omatala ma-na-kwa

this-CP.man-this man 3-stand in.front.of this-this-CP.thing

kali mata-la e-la o bwalita

fence eye-his 3-go Loc sea

'This man is standing in front of this fence, he is looking towards the sea'.

$\mathrm{Ka}$ bi-toli oluvale-la... ma-ke-na daga

well 3.FUT-stand in.the.middle.of-EMPH this-CP.wooden-this ladder

'well he will be standing in the middle of this ladder'

mna e-tota o la kikivama

$\mathrm{hm}$ 3-stand Loc his left

'it stands to his left'

o la kakata ma-kwela-na duram

Loc his right this-cP.pot.like-this drum

'To his right this drum'

oluvala-ga bi-toli. e mata-la bi-mikeya-m...

in.the.middle.of-емPн 3.FUT-stand and eye-his 3.FUT-come.to-you

'in the middle he will stand and his eye will come to you'

e bi-setaula bi-suvi... va geti turaki

and 3.FUT-go straight 3.FUT-enter DIR gate truck

'and he will go straight he will enter through the gate the truck' 
e-kanamwa a turakio $m$ kakatakali o $m$ kikivama

3-left.aside ah truck Loc your right fence Loc your left

'is left aside ah the truck at your right the fence at your left'

oluvala-ga bi-suvi.

in.the.middle.of-EMPH 3.FUT-enter

'in the middle he will enter'

'Well, he will be standing in the middle of this ladder, it is standing to his left (INTR), to his right (INTR) is this drum, in the middle he will be standing, and he will be looking at you (DEIC), and he will go straight he will enter through this gate, the truck is left aside, ah, the truck (is) at your right (REL), the fence at your left (REL), in between he will enter (this space)'.

In the first example we observe again the speaker's reference to the sea that serves as the landmark for describing the orientation of the little human figure in the route description game. In the second example, however, we note that the speaker may also use an expression like 'matala bimikeyam'-'he will be looking at you'; here the speaker is using deixis for describing the orientation of the little figure. However, this is not a counter-example to the observation that the absolute ad-hoc landmark frame of reference is generally preferred for describing the orientation of objects in space - it just shows that Kilivila offers the speaker another option. The second example also presents the use of intrinsic as well as relative 'left' and 'right' - and it is the possessive pronouns ${ }^{11}$ that make both usages unequivocal. Further use of relative 'left' and 'right' (observed in the Tinkertoy-games) is illustrated by the following expressions:

e-ma o m kakata
3-come LOc 2.POssPro right
it comes to your right (side)'
emwa o m kikivama
3-come.to LOC 2.POSsPro left
it comes to your left (side)'
e-ma o kuku-m
3-come LOc chest-2.POSSPRO
it comes to(wards) your chest'

Again, the second person of the possessive pronoun clearly marks the relative use of 'left' and 'right' and the relative frame of reference. 
Finally, in the 'maze-task game' we find acts of spatial reference like the following ones:

E e-lola e-ma e-suvi-la

And 3-walk 3-come 3-enter-EMPH

o la kakata o da-kikivama-si...

LOC his right LOC our-left-PL

'And he is walking, he is coming, he is entering indeed (the path) at his right (INTR), at our left (REL)'.

E ma-kada-na kedao la o la kakata...

Yes this-CP.path-this path LoC his Loc his right

Yes this path at his at his right

E va kona wa e-va'ila makala bi-la

and DIR corner only 3 -turn like 3.FUT-go

and at the corner only he turns like he will go

Tuyabwau e-va galai-la va kona

Tuyabwau.well 3-go to not 3-go DIR corner

Tuyabwau he goes to (it) he does not go there he goes to the corner

e-va'ila bila beya Kalavatu

3-turn 3.FUT-go there Kalavatu

he turns he will go there (to) Kalavatu

'Yes, this path at his at his right...(INTR) And only at the corner is he turning as if he will go to the Tuyabwau fresh water well, he does not go there, he goes to the (next) corner, he turns and he will go to there (where) Kalavatu (i.e. Kalavatu's house is)'.

Both these examples illustrate again the marked and unequivocal use of both intrinsic and relative 'left' and 'right' as well as the speaker's preference to use ad-hoc landmarks for describing the orientation of an object in space. These adhoc landmarks may refer to places outside of or within the maze that is used to elicit the route description.

These examples from my Kilivila corpus of spatial reference should suffice for illustrating and justifying my reformulation of our research hypothesis. We just have to ask what languages preferably use what frames of spatial reference in what contexts for what means and ends. Our research so far has shown that there are languages that indeed may prefer one specific system of verbal codification of spatial configurations in a broad variety of contexts and for all kinds of spatial references. However, this does not hold for Kilivila: On the one 
hand, speakers of this language obviously prefer the intrinsic frame of reference for the location of objects with respect to each other in a given spatial configuration - especially if these objects themselves have inherent intrinsic features. On the other hand, Kilivila speakers clearly prefer the absolute ad-hoc landmark frame of reference system in referring to the spatial orientation of objects in a given spatial configuration. Moreover, speakers may also use the relative frame of reference and deixis for referring both to the location and to the orientation of objects in space, however this is rather the exception than the rule. We have previously referred to Kilivila as a 'mixed language' with respect to its preferences for certain frames of spatial reference (see Pederson et al. 1998). On the basis of the findings and observations presented here I think that this is a rather misleading classification. To emphasize it once more: Speakers of Kilivila show rather clear preferences for certain frames of spatial reference in certain contexts for certain functions, for certain means and ends.

On the basis of these findings we may now have another look at Table 1 presented in Section 5 above. If we look at the row for Kilivila I have to concede that it was premature to list only the intrinsic and the relative frame of reference in the column for the preferred systems of verbal codification. The close intensive and time-consuming inspection of the data now reveals that I should have listed all three frames of reference - maybe with the relative frame of reference in brackets - under the column 'preferred system(s) of verbal codification'. My prediction for the system(s) of non-verbal codification was utterly wrong. On the basis of a sound data analysis I should have predicted the use of the intrinsic and the absolute frame of reference. But what about the results I obtained for my Kilivila consultants in the non-verbal experiments? Table 2 summarizes the results of the nonlinguistic tasks for the Kilivila speakers.

The preference for the absolute solutions in these memory experiments is evident. This need not surprise us. These experiments asked (among other things) for memorizing the orientation of certain objects/paths - and the analyses of the linguistic data have shown that Kilivila speakers prefer an absolute ad-hoc landmark Frame of reference system for referring to the spatial orientation of objects in a given spatial configuration. In 4 of 5 experiments the vast majority of my consultants used exactly the same system for a non-verbal codification of spatial configurations that emphasize the orientation of the objects/paths presented in the test. But what about the 'man and paths' experiment, our 'motion maze task'? This experiment tests recall and recognition memory with respect to movement in space and the transformation of movement into the construction of a path. The test consists of a figure resembling a 
Table 2. Results of the non-verbal experiments for Kilivila speakers

\begin{tabular}{llll}
\hline Experiment & \multicolumn{2}{l}{ No. of consultants with } \\
\cline { 2 - 4 } & $\begin{array}{l}\text { absolute } \\
\text { solutions }\end{array}$ & $\begin{array}{l}\text { relative } \\
\text { solutions }\end{array}$ & $\mathrm{N}$ \\
\hline 'animals in a row' & 16 & 0 & 16 \\
'red and blue chips' & 14 & 2 & 16 \\
$\quad 12$ & 4 & 16 \\
$\quad$ up/down axis & 15 & 1 & 16 \\
'ceft/right axis & 10 & 6 & 16 \\
'tranpleted path task' & 4 & 12 & 16 \\
'motion maze task' & & & \\
\hline
\end{tabular}

little man and a maze. Subjects look at the little man being walked by the experimenter in a certain complex path and should remember this path; they are then turned $180^{\circ}$ and are asked to select the endpoint on a maze where the little man would end up if he had followed that path and not others on the maze. It may well be that the scale of the maze and especially the man-like toy figure with its inherent intrinsic features made the consultants memorize the figure's movements using a 'left/right' system that in their solution to this memory task transformed into a relative system of spatial reference. However, I concede that this is a rather speculative attempt to explain the data. It refers back to the problem that we have many uncontrollable parameters (like, for example, in this task the possible influence of the size of the maze and of the movement of the figure) within the tests and experiments we devised to investigate non-verbal systems of spatial coding and their interrelation or correlation with verbal spatial coding systems. However, if we neglect the results of the 'motion maze-task' experiment, we can conclude that the results of the non-verbal experiments show a rather strong correlation with the results of the verbal codification of spatial configurations in Kilivila: Trobriand Islanders prefer an absolute ad-hoc landmark system for verbally referring to, and for memorizing, the orientation of objects in a given spatial configuration. Thus, the Kilivila data confirm the (reformulated) hypothesis also with respect to the fact that languages indeed seem to influence the choice and the kind of conceptual parameters their speakers use to solve non-verbal problems within the domain space. 


\section{Notes}

1. "The construction of the sciences ... does not progress rising higher and higher from foundations that are safe once and for all. On the contrary, every ascent to the heights requires from us the opposite effort and the opposite line of sight as well. In the midst of construction and extension we have to look back to the foundations - as Hilbert once characterized the proper goal of all theoretical science, we have to strive to lay the foundations deeper. If this holds for the exact sciences, then it holds to an even much greater degree for the humanities" (Cassirer 1938:230 [my translation, G.S.]).

2. This paper is based on research done by the following former or present members and guests of the "Language and Cognition" department, the former "Cognitive Anthropology Research Group" - the languages on which the members work and the respective LANGUAGE FAMILY are given in brackets behind the researcher's name: Giovanni Bennardo (Tongan, AUSTRONESIAN), Balthasar Bickel (Belhare, TIBETO-BURMAN), Penelope Brown (Tzeltal, MAYA), Eve Danziger (Mopan, MAYA), Susan Duncan (Chinese, SINOTIBETAN), James Essegbey (Ewe, NIGER-KORDOFANIAN), John Haviland (Guugu Yimithirr, PAMA NYUNGAN \& Tzotzil, MAYA), Deborah Hill (Longgu, AUSTRONESIAN), Kyoko Inoue (Japanese), Elizabeth Keating (Pohnpeian, AUSTRONESIAN), Anna Margetts (Saliba, AUSTRONESIAN), Sotaro Kita (Japanese), Lourdes de Leon (Tzotzil, MAYA), Paulette Levy (Totonac, TOTONAC), Sabine Neumann (Kgalagadi, BANTU), Eric Pederson (Tamil \& Bettu Kurumba, TAMIL), Eva Schultze-Berndt (Jaminjung \& Ngaliwurru, NON PAMA NYUNGAN), Christel Stolz (Yucatec, MAYA), Jürg Wassmann (Yupno, PAPUAN), Thomas Widlok (Hai//om, KHOISAN), David Wilkins (Mparntwe Arrernte, PAMA NYUNGAN), and Roberto Zavala (Oluta Popoluca, MIXE-ZOQUEAN). The director of the "Language and Cognition" department is Stephen C. Levinson (Guugu Yimithirr, PAMA NYUNGAN \& Tzeltal, MAYA).

We would like to thank all the institutions involved in granting us the permission to do research in their countries and we express our deep gratitude to all the native speakers of these languages, to our friends and consultants in our fields, for their friendly and patient cooperation.

3. These games were piloted for, and introduced to us by Lourdes de Leon and John Haviland with inspiration from Herbert Clark and Deanna Wilkes-Gibbes, Christiane von Stutterheim, and others. The method was further developed and finally revised by other members of our project, especially by Eve Danziger, Eric Pederson, Sotaro Kita, David Wilkins and also by Penelope Brown, Stephen Levinson, and Gunter Senft.

4. Charles Hendriks realized Sotaro Kita's (1995) design of these clips with the help of a three-dimensional animation program. For detailed descriptions of this method and the tasks that go with it see Kita (1995), Wilkins et al (1995), for first results see Kita (1999) and Senft (1999).

5. See Footnote 2 above.

6. I do not want to report this study in detail here. This study is reported in Wilkins and Senft (1994). 
7. The Kilivila orthography is based on Senft (1986:14f.). In the glosses I use the following abbreviations: $\mathrm{CP}=$ classificatory particle (classifier), $\mathrm{DEIC}=$ Deictic, $\mathrm{DEM}=$ demonstrative, $\mathrm{DIR}=$ directional, $\mathrm{EMPH}=$ emphasis, $\mathrm{FUT}=$ future, $\mathrm{INTR}=$ intrinsic, $\mathrm{INCL}=$ inclusive, $\mathrm{LOC}=$ locative, $\mathrm{PL}=$ plural, $\mathrm{POSSPRO}=$ possessive pronoun, $\mathrm{REL}=$ relative

8. For data and results with respect to the 'Tinkertoy-games' and the 'Enter/Exit-game' see Senft (1994b, 1999).

9. In Kilivila the instrinsic frame of reference is clearly preferred for the location of objects in relation to each other especially if these objects have instrinsic features. As illustrated in Section 6 above we also observe the use of the relative-deictic frame of reference in Kilivila speakers - however, they use the relative system rather rarely in my corpus of data on spatial reference.

10. The "route direction games" — as well as the "maze-task games" — were documented on video-tape. Alas, I cannot illustrate these situations in print.

11. Kilivila has a fourfold series of possessive pronouns that are partly realized as free possessive pronominal pronoun forms and partly realized as possessive pronominal affixes. One of these series refers to food only, the other three series are used to distinguish different degrees of possession. For details see Senft (1986:47-54).

\section{References}

Bühler, Karl. 1934 (=1978). Sprachtheorie. Die Darstellungsfunktion der Sprache. Jena: Gustav Fischer. Frankfurt am Main: Ullstein.

Brown, Penelope, and Stephen C. Levinson. 1993. Linguistic and Nonlinguistic Coding of Spatial Arrays: Explorations in Mayan Cognition. CARG Working paper No. 24. Nijmegen: MPI for Psycholinguistics.

Cassirer, Ernst. 1938. (=1994). Zur Logik des Symbolbegriffs. Die Philosophie der symbolischen Formen. Sonderausgabe: Wesen und Wirkung des Symbolbegriffs. 201-230. Darmstadt: Wissenschaftliche Buchgemeinschaft.

Danziger, Eve, ed. 1993. Cognition and Space Kit of the Cognitive Anthropology Research Group. Nijmegen: MPI for Psycholinguistics.

Hill, Deborah, ed. 1993. Manual for the Space Stimuli Kit of the Cognitive Anthropology Research Group. Nijmegen: MPI for Psycholinguistics.

Kita, Sotaro. 1995. "Enter/Exit Animation for linguistic elicitation”. In Wilkins, David (ed.), Extensions of Space and Beyond: 'Manual' for Field Elicitation for the 1995 Field Season. 13. Nijmegen: MPI for Psycholinguistics.

Kita, Sotaro. 1999. "Japanese Enter/Exit Verbs without Motion Semantics". Studies in Language 23: 307-330.

Klein, Wolfgang. 1991. "Raumausdrücke". Linguistische Berichte 132: 77-114.

Levinson, Stephen C. 1992. "Primer for the field investigation of spatial description and Conception”. Pragmatics 2: 5-47.

Levinson, Stephen C. 1996a. "Language and Space". Annual Review of Anthropology 25: 353-382. 
Levinson, Stephen C. 1996b. Frames of reference and Molyneaux's question: Cross-linguistic evidence. In Bloom, Paul, Mary A. Peterson, Lynn Nadel, and Merrill Garrett, eds., Language and Space. 109-169. Cambridge, MA: MIT Press.

Levinson, Stephen C., and Gunter Senft. 1991. "Research Group for Cognitive Anthropology - A New Research Group of the Max Planck Society”. Cognitive Linguistics 2: 311-312.

Nüse, Ralf. 1996. "Über die Realitätsadäquatheit der phänomenalen Welt oder Things look as they do because they are what they are". GESTALTTHEORIE 18: 52-67 \& 86-114.

Pederson, Eric. 1993. "Geographic and manipulable space in two Tamil linguistic systems. Spatial Information Theory". In Frank, Andrew U. and Irene Campari (eds.), A theoretical Basis for GIS, 294-311. Berlin: Springer.

Pederson, Eric and Gunter Senft. 1996. "Route Descriptions: Interactive Games with Eric's Maze Task”. CARG Manual for the 1996 Field Season. 15-18. Nijmegen: MPI for Psycholinguistics.

Pederson, Eric, Eve Danziger, David Wilkins, Stephen Levinson, Sotaro Kita, and Gunter Senft. 1998. "Semantic typology and spatial conceptualization”. Language 74: 557-589.

Senft, Gunter. 1986. Kilivila — The Language of the Trobriand Islanders. Berlin: Mouton de Gruyter.

Senft, Gunter. 1994a. "Ein Vorschlag, wie man standardisiert Daten zum Thema 'Sprache, Kognition und Konzepte des Raumes' in verschiedenen Kulturen erheben kann“. Linguistische Berichte 154: 413-429.

Senft, Gunter. 1994b. "Spatial Reference in Kilivila: The Tinkertoy Matching Games — A Case Study". Language and Linguistics in Melanesia 25: 55-93.

Senft, Gunter. 1995a. "Sprache, Kognition und Konzepte des Raumes in verschiedenen Kulturen“. Kognitionswissenschaft 4: 166-170.

Senft, Gunter. 1995b. "Elicitation”. In: Blommaert, Jan, Jan-Ola Östman, and Jef Verschueren (eds.), Handbook of Pragmatics, Manual. 577-581. Amsterdam: John Benjamins.

Senft, Gunter. 1997. "Introduction”. In Senft, Gunter (ed.), Referring to Space — Studies in Austronesian and Papuan Languages, 1- 38. Oxford: Clarendon Press.

Senft, Gunter. 1999. "ENTER and EXIT in Kilivila”. Studies in Language 23: 1-23.

Senft, Gunter. 2000. "COME and GO in Kilivila”. In Palmer, Bill and Paul Geraghty (eds.), SICOL. Proceedings of the Second International Conference on Oceanic Linguistics: vol. 2, Historical and descriptive studies, 105-136. Pacific Linguistics Series. Canberra: Australian National University.

Talmy, Leonard. 1978. "Figure and Ground in Complex Sentences". In Greenberg, Joseph H. (ed.), Universals of Human Language, Vol iv: Syntax, 625-649. Stanford: Stanford University Press.

Weissenborn, Jürgen. 1986. "Learning how to become an interlocutor — The verbal negotiation of common frames of reference and actions in dyads of 4-14 year old children”. In Cook-Gumperz, Jenny, William A. Corsaro; and Jürgen Streeck (eds.), Children's worlds and children's language, 377-404. Berlin: Mouton de Gruyter.

Wilkins, David and Gunter Senft. 1994. A man, a tree, and forget about the pigs: Space games, spatial reference and cross-linguistic comparison. Plenary paper presented by G. Senft at the 19th International L.A. U.D.-Symposium 'Language and Space', Duisburg. Nijmegen: MPI for Psycholinguistics. 
Wilkins, David and Deborah Hill. 1995. "When 'GO' means COME': Questioning the basicness of basic motion verbs". Cognitive Linguistics 6: 209-259.

Wilkins, David, Eric Pederson, and Stephen Levinson. 1995. "Background Questions for the 'Enter'/' Exit' research”. In Wilkins, David (ed.), Extensions of Space and Beyond: 'Manual' for Field Elicitation for the 1995 Field Season, 14-16. Nijmegen: MPI for Psycholinguistics.

\section{Author's address}

Max-Planck-Institute for Psycholinguistics

PB 310

NL-6500 AH Nijmegen

The Netherlands

gunter@mpi.nl 